\title{
0 corpo em ruptura como espaço de diferenças
}

\author{
Manabu Noda
}

Gostaria de começar com uma afirmação: o corpo teatral é o corpo que incorpora, do mesmo modo que visualiza, forças opostas e contraditórias. Veja-se o exemplo de Charlie Chaplin. Na sua postura mais formal, o seu peito está projectado para fora, compensado pelos ombros e pela bacia numa postura mais recuada, o que cria a forma exagerada do pombo. Esta é basicamente uma postura que envolve uma grande tensão - imagine-se um novo recruta apreensivo enfrentando o seu sargento de instrução -, mas as suas pernas em arco, que levantam a sua pélvis, sugerem uma juvenilidade descontraida que se esconde por detrás daquela formalidade. Na sua postura mais vulnerável, o peito retrai-se, exibindo humildade e vulnerabilidade, mas a parte inferior do seu corpo abre-se com a pélvis mais projectada para a frente, indicando virilidade e arrogância. Combinado com o seu figurino idiossincrático, o corpo de Chaplin é feito de contradições e oposições, tanto em termos de dinâmica como de afirmações de classe, combinando vulnerabilidade e arrogância de um modo irreconciliável. Daí a sua imprevisibilidade como personagem cómico.

Nas tradições teatrais japoneses do Nō e do Kyogen, a posição neutral caracteriza-se pela postura com o peito projectado e os ombros e as ancas recuadas. Os joelhos aparecem dobrados, mas não em forma de arco, de modo que a pélvis fica voltada para baixo. Colocando ambas as mãos no colo e puxando os ombros para trás, fica-se na posição padrão do actor de Nō/Kyogen. Esta posição

neutral força um pouco a anatomia do actor, tornandoo consciente do funcionamento dos músculos dentro do seu corpo, o que the permite equilibrar forças contrárias. Tadashi Suzuki, do famoso Método Susuki, aplica este mecanismo ao seu sistema de formação de actores, servindo-se desta posição neutral para ajudar o actor a controlar o funcionamento interno do seu corpo.
A maior parte das tradições teatrais japonesas insistem na proximidade do corpo relativamente à terra. Em sentido contrário, as tradições ocidentais tendem a sublinhar mais a aspiração do corpo pelo céu. 0 bailado é o exemplo mais característico. 0 corpo é esticado verticalmente em direcções opostas entre o céu e a terra. Esta diferença nas tradições teatrais entre o Oriente e o Ocidente é muitas vezes explicada como cultural: a posição mais baixa e mais ligada à terra do Oriente baseia-se na convicção de que o actor extrai as suas forças da Mãe Terra, enquanto a posição esticada ocidental tenta resistir à gravidade, praticando uma fisicalidade mais etérea e aspirando ao céu como um domínio de pura espiritualidade. Em termos do equilibrio consciente de tensões interiores opostas e contraditórias, contudo, as duas tradições partilham 0 mesmo princípio. As técnicas do Nō/Kyogen e do bailado incorporam literalmente as diferenças através da criação voluntária de sentidos que são gerados tanto pelo actor como pelo público. É neste momento que o corpo atravessado por fissuras e rupturas, rasgado por forças discursivas opostas e aparentemente contraditórias, se torna um espaço de diferenças. Esta reflexão debruça-se sobre três tipos de fissuras, neste plano, e das suas manifestações no teatro japonês: o género ou diferença sexual, a oposição Oriente/Ocidente e a dimensão política.

\section{Fissura de género}

É natural que os fazedores de teatro tirem partido das tradições bem estabelecidas que incorporam diferenças de um modo claramente visual para o seu público. A tradição do onnagata, ou representação do feminino, do Kabuki é, sem dúvida, um bom exemplo. A força teatral da representação do travestimento no Kabuki assenta na necessidade sentida pelo intérprete de constantemente questionar e rever a construção masculina das mulheres num plano ideal.
Manabu Noda

é Professor na Escola das Artes e das Letras, da Universidade de Meiji, em Tóquio, é também crítico e investigador, tendo publicado livros e ensaios sobre o teatro japonês e britânico. 
Um exemplo é a encenação de Noite de reis por Yukio
Ninagawa numa abordagem completamente dominada por um estilo Kabuki. Uma vez que a divisão física a nível da diferença sexual é clara no texto, a técnica do onnagata do Kabuki revelou-se extremamente eficaz na teatralização da incerteza de género. Pense-se, por exemplo, na cena em que Viola/Cesário, já apaixonada por Orsino, recebe instruções para ir cortejar Olivia em nome do seu senhor. Onoe Kikunosuke, que interpretava Viola/Cesário, alternava sem qualquer esforço entre os dois sexos recorrendo à representação altamente estilizada do Kabuki, particularmente impressionante quando, de vez em quando, a rapariga Viola não resistia em emergir à superfície do rapaz Cesário. Era uma interpretação deslumbrante, que criava uma sensação agradável e também estonteante de incerteza.

\section{A fissura Oriente/Ocidente}

As fissuras físicas podem aparecer ao longo da divisão Oriente/Ocidente em consequência de uma espécie de auto-imposto Orientalismo no Japão, reservando a mente ao Ocidente e o corpo ao Oriente. Numa entrevista, Ninagawa explicava porque é que ficou tão impressionado com o espectáculo de Butō de Tatsumi Hijikata, Vinte e sete noites para as quatro estações (Shiki-no tameno Nijūshichi-ban, 1972). Ele sentiu uma forte identificação com o modo como Hijikata encenou a memória do Japão após o início do processo de modernização/ocidentalização:

Ele estava em busca da origem do Japão sustentada pelo intelecto europeu. (...) Cores pré-modernas eram abruptamente introduzidas nos figurinos e nos adereços. Quando vi Hijikata, com o seu longo cabelo toscamente amarrado e vestido com a sua tanga branca japonesa, com uma outra peça de tecido à volta da cintura, ele parecia exactamente Jesus Cristo. Servindo-se de icones japoneses caracteristicamente pré-modernos, ele conseguiu alcançar a elevação
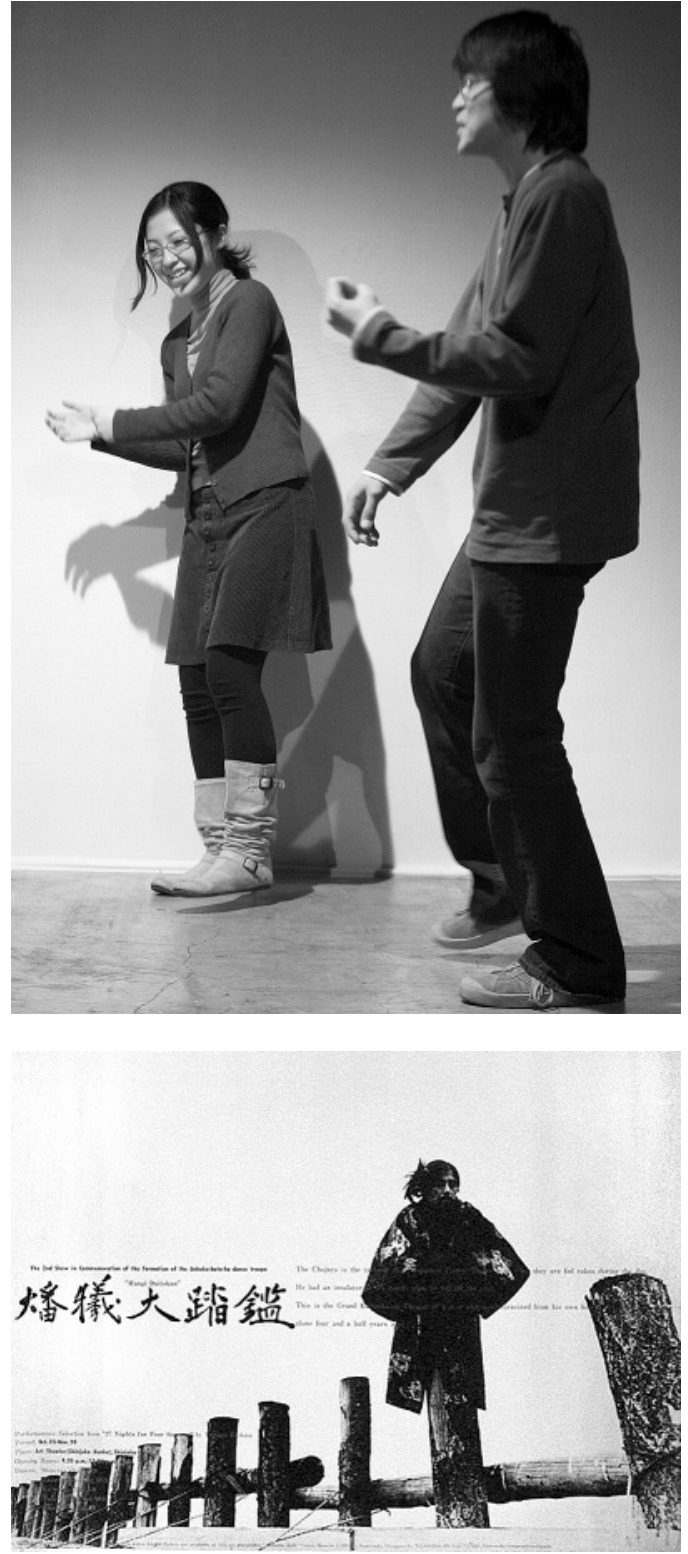

espiritual do Ocidente. Achei extremamente interessante o modo como ele ligou o Japão e o Ocidente. (Takahashi 2001: 87-88

0 corpo de Hijikata absorvia aqui a fissura entre o Japão oriental e pré-moderno (isto é, pré-ocidentalizado) e o Ocidente representado pelo seu mais forte ícone religioso. Era uma fissura criada ao longo do processo de ocidentalização do Japão, e a dupla imagem criada por Hijikata - o primitivismo japonês e o cristianismo ocidental - surgia sobreposta a uma outra dupla imagem favorita do criador japonês: a do feto e do cadáver.

\section{Fissura política}

As fissuras físicas em palco podem também resultar de pressões políticas exteriores. 0 início do século XXI ficou marcado pelo corpo constrangido no teatro japonês, sem dúvida em resultado da administração de centro-direita de Jun'ichirō Koizumi entre 2001 e 2006, que foi também o periodo em que a sobrevivência dos mais fortes se tornou a norma na economia de mercado globalizada, enquanto uma política mais dura e agressiva ia ganhando espaço nas relações com o exterior, especialmente no que diz 


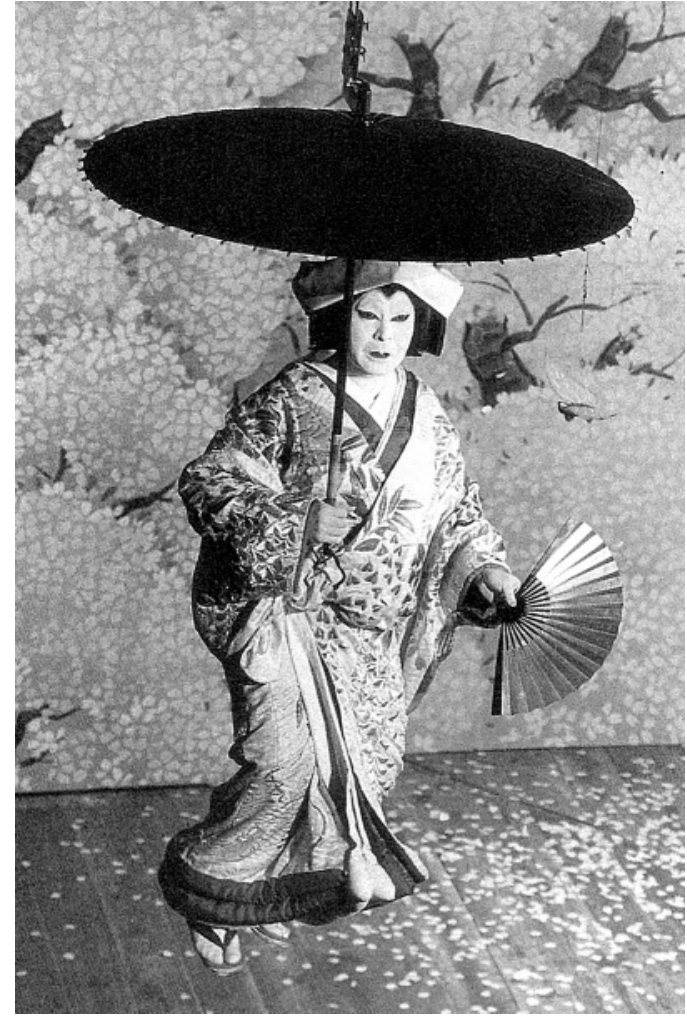

respeito à Coreia do Norte (cf. Noda 2007). 0 desvio físico presente no corpo teatral japonês constrangido tende para o medo e para a ansiedade, sobretudo face à incapacidade individual de se adaptarem e assimilarem as circunstâncias politicamente duras, que conduzem à introversão e ao recolhimento em resultado das pressões do exterior.

O espectáculo Cinco dias em Março (2004), de Toshiki Okada, apresentava o corpo constrangido de um modo que se revelava muito sintomático do Japão sob o governo de Koizumi e da nova ordem mundial após o 11 de Setembro. 0 desconforto físico podia ir até ao desenvolvimento de espasmos. Numa cena da peça, dois jovens encontram-se no cinema e começam a conversar sobre se devem ir ver um concerto do grupo que fez a banda sonora do filme que acabaram de ver. A rapariga, embora tentando seduzir o rapaz, é como que possuída por um ataque de maneirismos incessantes, de tal modo que os seus movimentos se aproximam de espasmos patológicos. Podemos ver nela a frustração por se sentir tão inepta a comunicar. Após esta cena, voltamos a vêla em casa, revoltada consigo própria e escrevendo no seu blogue sobre o seu sonho de escapar para Marte. 0 corpo constrangido aparece aqui associado ao escapismo.

As fissuras que discuti não são de algum modo exaustivas, mas eu ainda acredito que vale a pena sublinhar que estas fissuras no corpo - sejam elas cinéticas, técnicas ou discursivas - transformam o corpo num espaço de produção de sentido de um modo susceptivel de proporcionar o Verfremdungseffekt brechtiano, através do qual se espera que o reconhecimento dos aspectos físicos da nossa vida seja renovado e revisto. As fissuras dividem por definição; as divisões criam diferenças; e as diferenças produzem sentidos. As fissuras são, assim, o espaço em que os sentidos são produzidos. Ao mesmo

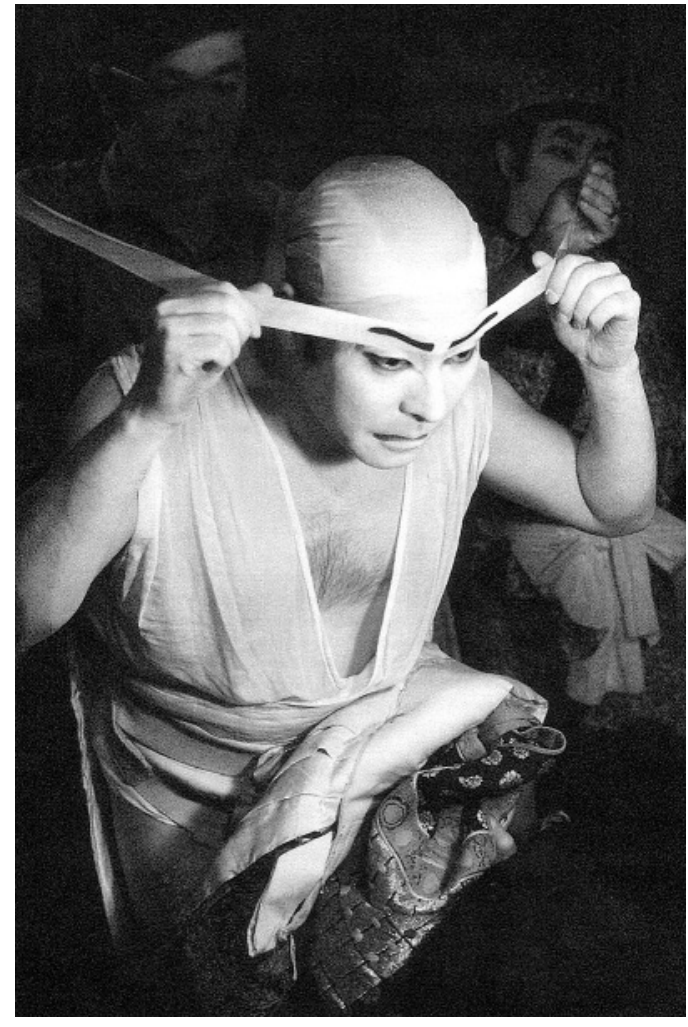

Ennosuke em plena actuação.

0 actor Ennosuke preparando-se para um travestimento rápido, fot. Hanabusa Lyu.

tempo, as fissuras não são uma terra de ninguém entre uma qualquer tese e a sua antítese e, como tais, vazias de sentido. 0 público não pode deixar de atribuir sentido a tudo o que vê em palco, mas ao fazê-lo é também inevitavelmente confrontado com o vazio. Assim, o palco é um lugar tanto de produção como do seu contrário. Tal como a mandala de areia tibetana que tem de ser destruída uma vez concluída a sua construção, qualquer obra teatral bem concebida deverá significar para o seu público uma viagem que desafie o fechamento. Embora seja tarefa do crítico identificar as forças opostas que criam fissuras, isso não significa que o crítico possa dar uma forma final a essa obra. Continua a ser, contudo, possivel tentar descrever o modo como o processo de produção - e do seu contrário - é tornado possível, sem privilegiar de forma incondicional a presença fisica no palco como algo que transcende o sentido.

\section{Referências bibliográficas}

NODA, Manabu (2007), "The Body III at Ease in Post-War Japanese Theatre", New Theatre Quaterly, 23: 3, August, pp. 272-82.

TAKAHASHI, Yutaka (2001), Ninagawa Yukio Densetsu [A lenda de Yukio Ninagawa], Tóquio, Kawade Shobo Shinsha.

Tradução de Paulo Eduardo Carvalho 